TITLE:

\title{
Microscopic analysis of particle detachment from an obliquely oscillating plate
}

\section{AUTHOR(S):}

Kobayakawa, Murino; Kiriyama, Seiya; Yasuda, Masatoshi; Matsusaka, Shuji

\section{CITATION:}

Kobayakawa, Murino ...[et al]. Microscopic analysis of particle detachment from an obliquely oscillating plate. Chemical Engineering Science 2015, 123: 388-394

\section{ISSUE DATE:}

2015-02

URL:

http://hdl.handle.net/2433/193259

\section{RIGHT:}

(c) 2014 Elsevier Ltd.; この論文は出版社版でありません。引用の際には 出版社版をご確認ご利用ください。; This is not the published version. Please cite only the published version. 


\title{
Microscopic analysis of particle detachment from an obliquely oscillating plate
}

\author{
Murino Kobayakawa, Seiya Kiriyama, Masatoshi Yasuda, Shuji Matsusaka* \\ Department of Chemical Engineering, Kyoto University, Kyoto 615-8510, Japan \\ * Corresponding author. \\ E-mail address: matsu@cheme.kyoto-u.ac.jp (S. Matsusaka)
}

Keywords: Powder technology; Oblique oscillation; Particle detachment; Microscopic analysis; Moment balance

\begin{abstract}
Particle detachment from an obliquely oscillating plate was studied experimentally and theoretically. The plate was placed in a horizontal position, and vibrations were applied in the horizontal and vertical directions by piezoelectric vibrators. The frequency of vibration was constant at $280 \mathrm{~Hz}$. The amplitude of vibration increased with time and approached a constant value in each experiment. The movement of micrometer-sized spherical particles was analyzed using images captured by a highspeed microscope camera, which showed that the particles rolled on the plate before detaching from the surface, and that the rolling significantly reduced the adhesive force between the particles and surface. Furthermore, the removal efficiency, defined by the number ratio of detached particles to total particles, was analyzed as a function of the horizontal and vertical vibration accelerations. It was found that the removal efficiency was significantly affected by the horizontal vibration acceleration. These experimental results can be explained by the force and moment balance model.
\end{abstract}




\section{Introduction}

The external force created by vibration has been used to fluidize particles. Particles under vibration exhibit various unusual behaviors, such as convection (Yang and Hsiau, 2000; Yang and Hsiau, 2001; Chung et al., 2013), bubbling (Pak and Behringer, 1994; Zamankhan, 2011a,b), segregation (Rosato et al., 2002; Yang, 2006; Liao et al., 2010), and vibration-induced air inflow (Matsusaka et al., 2013). Particle fluidization under vibration has numerous engineering applications, such as fluidized beds (Tatemoto et al., 2004; Tatemoto et al., 2005; Limtrakul et al., 2007; Quintanilla et al., 2008), conveyors (Gallas et al., 1992; Rademacher and ter Borg, 1994; Sloot and Kruyt, 1996; Simsek et al., 2008), micro-feeders (Matsusaka et al., 1995, 1996) and evaluation methods for powder flowability (Jiang et al., 2006, 2009; Ishii et al., 2011; Zainuddin at al., 2012).

The vibrating conveyor, i.e., an obliquely oscillating trough inducing two-dimensional motion of a particle bed, is one of the simplest systems of particle fluidization under vibration, and has been investigated extensively (Gallas et al., 1992; Rademacher and ter Borg, 1994; Sloot and Kruyt, 1996; Simsek et al., 2008). However, in most previous studies of this system, adhesive and cohesive forces and fluid resistance were neglected because the studies have been carried out using non-cohesive, coarse particles with diameters larger than several hundred micrometers.

Particle behavior on an obliquely oscillating plate can be divided into three states: adhesion to the surface, detachment, and saltation. We previously studied the saltation of particles with a range of 0.5$500 \mu \mathrm{m}$ in mass median diameter (Kobayakawa et al., 2014a,b). However, the process of particle detachment has not been studied.

There are several methods for removing fine particles from surfaces: (i) centrifugal separation (Matsusaka et al., 1997; Salazar-Banda et al., 2007), (ii) vibration separation (Mullins et al., 1992; Theerachaisupakij et al., 2002; Hubbard et al., 2012), (iii) aerodynamic drag separation (Kousaka et al., 1980; Wang, 1990; Tsai et al., 1991; Matsusaka et al., 1991, 1997; Matsusaka and Masuda, 1996; 
Jiang et al., 2008; Maniero et al., 2012), and (iv) kinetic separation based on the impact of aerosol particles (Theerachaisupakij et al., 2002, 2003; Liu et al., 2011, 2012). Three main mechanisms for removal have been proposed: (i) rolling, (ii) sliding and (iii) lifting. From theoretical analyses using the force and moment balance model, it has been shown that the removal of spherical particles is more easily achieved by rolling, rather than sliding or lifting (Kousaka et al., 1980; Wang, 1990; Tsai et al., 1991; Matsusaka et al., 1991; Soltani and Ahmadi, 1994; Soltani et al., 1995). Although many studies on removal from the surface have been conducted, the process from rolling to detachment is not yet clear. To fully elucidate the mechanism of particle detachment, the phenomenon needs to be observed microscopically.

In this paper, the mechanism of detachment of micrometer-sized spherical particles from an obliquely oscillating plate is presented. In order to clarify the relationship between the phase angle of the oscillating plate and the motion of the particles, the particle behavior, trajectories, and velocities are analyzed from images captured by a high-speed microscope camera, and the experimental results are discussed using a force and moment balance model. Furthermore, the effects of the horizontal and vertical accelerations of the oscillating plate on the particle removal efficiency are elucidated.

\section{Materials and methods}

Fig. 1 shows a schematic diagram of the experimental setup. A stainless steel plate (SUS304, 15×15 $\mathrm{mm}^{2}$ ), the surface of which was treated by abrasive blasting to create a homogeneous state, was mounted on a shock absorber. The micro-roughness of the surface was measured by a confocal laser scanning microscope (LEXT OLS4000, Olympus Corporation). The plate was sinusoidally oscillated in both horizontal and vertical directions by piezoelectric vibrators. There was no phase difference between the waves applied in the two directions. The frequency was set at $280 \mathrm{~Hz}$, which corresponds to the natural frequency of the apparatus, so that large vibration amplitudes could be obtained. The 
amplitude could be adjusted by the applied voltage. The vibrators were controlled by a vibration control system (VST-01, IMP. Co., Ltd.).

Zirconia particles (Tosoh Corporation, particle density $\rho_{p}=5900 \mathrm{~kg} / \mathrm{m}^{3}$ ) were used in the experiments. The particles were observed through a scanning electron microscope (VE9800, Keyence Corp.). Fig. 2 shows an SEM image of the particles. All the particles are spherical and have smooth surfaces. Fig. 3 shows the number based particle size distribution, in which 100 particles were counted. The particle diameter was in the range of $48-68 \mu \mathrm{m}$ and the median diameter $D_{p 50}$ was $57 \mu \mathrm{m}$. The geometry standard deviation $\sigma_{\mathrm{g}}$ was 1.07 , indicating a narrow size distribution. The particles were dried at $120^{\circ} \mathrm{C}$ over $24 \mathrm{~h}$ and cooled down to room temperature in a desiccator. The particles were distributed on the metal plate through a sieve. To avoid collisions between particles, the area covered by the particles was less than $0.5 \%$ of the total surface area.

The plate and the particles were illuminated by LED light (UFLS-75, U-Technology Co., Ltd.), and observed through a high-speed microscope camera with a resolution of $1 \mu \mathrm{m}$ (Fastcam Mini UX100, Photron, Ltd.). The images were recorded at a rate of 8,000-12,500 frames per second (fps) and analyzed via digital image processing (Dipp-Motion 2D, Detect Co., Ltd.). The particle removal efficiency was determined by digital counting of the number of particles adhering to the plate before and after each experiment. All the experiments were conducted at $20 \pm 2{ }^{\circ} \mathrm{C}$, and the relative humidity was controlled at 30-40\% to avoid disturbances caused by liquid bridge forces.

\section{Results and discussion}

\subsection{Two-dimensional vibration of the plate}

Fig. 4(a) shows the displacement of the oscillating plate as a function of time; the values were obtained from the images captured by the high-speed microscope camera at a frame rate of 12,500 fps. The experimental results indicate that the amplitude of vibration increased with time and approached 
a constant value after 100 ms. Fig. 4(b) shows a magnified view of the oscillation wave between 70 and $100 \mathrm{~ms}$. The plate was sinusoidally oscillated. The angular velocity was $1760 \mathrm{rad} / \mathrm{s}$, and the period of each cycle was $3.6 \mathrm{~ms}$, which corresponds to a vibration frequency of $280 \mathrm{~Hz}$.

Fig. 5 shows the Lissajous figures of the oscillating plate over ten cycles after the vibration amplitude reached a steady-state. The controllable ranges of the horizontal and vertical amplitudes were 5-60 $\mu \mathrm{m}$ and 5-45 $\mu \mathrm{m}$, respectively. In this figure, three patterns are shown: $\left(A_{x}, A_{y}\right)=(60,5)$, $(60,45),(5,45)$. In these conditions, the two sine waves were synchronized and formed an inclined linear vibration. The repeatability was found to be sufficiently high.

\subsection{Particle motion}

The amplitude of vibration increased with time, as shown in Fig. 4(a). The particles adhering to the plate were removed when the separation force overcame the gravitational and adhesive forces.

Fig. 6 shows five selected snapshots of the process of particle detachment from the oscillating plate during one oscillation cycle. The snapshots were captured by the high-speed camera at a frame rate of 8000 fps. The $x$ and $z$ coordinates are defined by setting the $x$-axis and $z$-axis tangential and normal (upward) to the plate, respectively. The value of zero in the phase angle indicates the onset of the relative motion of the particle with respect to the plate. The upward white arrows denote the initial contact point of the plate with the particle. When the plate is moving upward and downward, the plate is moving forward and backward, respectively, because the vibration waves in the two directions are synchronized. Before 0 rad, the particle adhered to the oscillating plate. For $0-\pi$ rad, the particle rolled forward on the plate due to the particle inertia and the friction force on the surface, which was moving downward and backward. When the direction of the plate motion reversed at $\pi$ rad, the particle began to roll backward. At $2 \pi \mathrm{rad}$, the particle was airborne and rotating.

Fig. 7 shows the horizontal and vertical displacements of the oscillating plate and the particle as a 
function of the phase angle of the oscillation. The displacements were tracked by digital processing of a series of the images taken at 8000 fps for the experiment, as shown in Fig. 6. In the vertical axis, zero corresponds to the center of oscillation. The solid lines and dashed lines in these graphs indicate the displacements of the oscillating plate and the particle, respectively. The particle displacement is drawn assuming zero radius. For reference, the scale of the vibration acceleration corresponding to the displacements is included on the right side vertical axis of the figure. In Fig. 7(a), the horizontal displacement of the plate at $2 \pi$ rad was larger than that at 0 rad because the vibration amplitude increased with time. Before 0 rad, the horizontal displacement of the particle was the same as that of the plate, showing that the particle adhered to the oscillating plate at $\alpha_{x}=-80 \mathrm{~m} / \mathrm{s}^{2}$. For $0-\pi \mathrm{rad}$, the particle rolled forward; thus, the horizontal movement of the particle was delayed compared to that of the plate. After $\pi \mathrm{rad}$, the particle rolled backward; as a result, the particle moved backward relative to the plate.

From Fig. 7(b), it can be seen that the dashed line overlaps the solid line for approximately $0-3 \pi / 2$ rad, indicating that the particle was in contact with the plate because of the gravitational and adhesive forces. After the particle is detached from the surface, the dashed line parts from the solid line.

To identify the phase angle of particle detachment, the vertical velocities as a function of time are shown in Fig. 8(a). The instantaneous velocities were obtained from the time derivatives of the positions between two successive images (time interval: $0.125 \mathrm{~ms}$ ). The velocity of the particle was equal to that of the plate before $1.53 \pi$ rad and subsequently slightly decreased with time. In addition, a magnified view of Fig. 7(b) is shown in Fig. 8(b). From this graph, the vertical acceleration $\alpha_{z}$ of the plate for the detachment was $-10 \mathrm{~m} / \mathrm{s}^{2}$.

The particle can detach when the vertical component of the vibration force exceeds the sum of the gravitational and adhesive forces between the particle and the plate. In Fig. 7(b), the particle was still in contact with the plate under a vertical acceleration of $-80 \mathrm{~m} / \mathrm{s}^{2}$ at 0 rad. However, as shown in Fig. 
8(a), the particle could detach under an acceleration of $-10 \mathrm{~m} / \mathrm{s}^{2}$. This indicates that the adhesive force decreased to almost zero during rolling, because the gravitational force per unit mass remained at -9.8 $\mathrm{m} / \mathrm{s}^{2}$.

\subsection{The force and moment balance model}

In order to explain the mechanisms for the particle behavior explained in Section 3.2, we compare a rolling model with a lifting model. Fig. 9 illustrates the forces acting on a particle adhering to an obliquely oscillating rough surface. There are four main forces: the horizontal $\left(F_{s x}\right)$ and vertical $\left(F_{s z}\right)$ components of the separation force caused by the vibration acceleration, gravitational force $\left(F_{g}\right)$, and the adhesive force $\left(F_{a}\right)$. The moment balance for rolling is expressed as

$$
2 F_{a}+F_{g}=\left(\sqrt{\left(\frac{D_{p}}{2 a}\right)^{2}-1}\right) F_{s x}+F_{s z}
$$

where $D_{p}$ is the diameter of the particle and $a$ is the contact radius between the particle and the plate. When the moment of forces caused by $F_{s x}$ and $F_{s z}$ is greater than the moment of forces caused by $F_{g}$ and $F_{a}$, the particle rolls on the surface.

For lifting, the balance of the forces in the vertical direction is represented by

$$
2 F_{a}+F_{g}=F_{s z}
$$

When the separation force $\left(F_{s z}\right)$ is larger than the downward forces $\left(F_{g}\right.$ and $\left.F_{a}\right)$, the particle lifts off from the surface.

The comparison between Eq. (1) and (2) shows that rolling occurs more easily than lifting because of the contribution of the first term of the right-hand side of Eq. (1). As mentioned in Section 3.2, the maximum separation force $F_{s}$ in each oscillation cycle increases with time. As a result, the particle rolls on the surface before the lift off. After the particle rolls on the plate, the particle can detach within one oscillation cycle because the rolling significantly reduces the adhesive force between the particle 
and the plate, as shown in Fig. 8.

The decrease in the adhesive force can be explained as follows: although the adhesive force generally consists of the van der Waals force, liquid bridge force, and electrostatic force, the latter two forces can be neglected in our experiment because of low humidity and small electrostatic charge. The adhesive force based on the van der Waals interaction between the particle and the plate is given by

$$
F_{a}=\frac{A D_{p}}{12 z_{0}^{2}}
$$

where $A$ is the Hamaker constant and $z_{0}$ is the separation gap between the particle and plate, which is usually taken as $0.4 \mathrm{~nm}$ for smooth surfaces. This equation indicates that the force decreases inversely with the square of the separation gap. Although the gap increases to only several tens of nanometers during rolling, the force is drastically reduced. As a result, the adhesive force is negligible compared to gravitational force during rolling.

\subsection{Removal efficiency as a function of the horizontal and vertical acceleration}

To discuss the effects of the horizontal and vertical forces on the removal efficiency, the particles adhering to the plate were removed under different horizontal and vertical accelerations. The removal efficiency, $\eta$, is defined as

$$
\eta=\frac{N_{0}-N_{r}}{N_{0}}
$$

where $N_{0}$ is the initial number of particles adhering to the plate and $N_{\mathrm{r}}$ is the number of residual particles.

Fig. 10 shows the relationship between the removal efficiency and the vertical amplitude as a parameter of the horizontal amplitude. For reference, the scale of the vibration acceleration of the plate, which corresponds to the amplitude, is included on the upper side of the graph. The initial number of particles, $N_{0}$, was set to 200 . The upper and lower error bars of the mean value indicate the standard 
deviation for three experiments. The removal efficiency slightly increased with the vertical amplitude. A higher horizontal amplitude significantly increased the removal efficiency. This was because the higher horizontal amplitude induced particle rolling, which decreased the adhesive force between the particles and plate, as shown in Fig. 8.

Fig. 11 shows the relationship between the removal efficiency and the horizontal amplitude as a parameter of the vertical amplitude. The removal efficiency significantly increased with the horizontal amplitude in the range of 5-20 $\mu \mathrm{m}$, while the vertical amplitude had little effect. To discuss this phenomenon according to the moment balance of Eq. (1), the value of the contact radius $a$ between the particle and plate is needed.

To estimate the contact radius, we measured the surface roughness of the plate and particles by a laser microscope. Fig. 12 shows a three dimensional image of the plate. The roughness was uniformly distributed over the surface due to abrasive blasting. Fig. 13 shows the profiles of the surface roughness along the $y$ axis at $x=\mathrm{S} 1, \mathrm{~S} 2$, and S3 in Fig. 12. The average roughness $R_{a}$ of each profile was in a range from 0.24 to $0.32 \mu \mathrm{m}$. Fig. 14 shows a three dimensional image of a zirconia particle. The particle was spherical and very smooth. Fig. 15 shows the profiles of the surface roughness along the $y$ axis at $x=\mathrm{P} 1, \mathrm{P} 2$, and P3 in Fig. 14. The average roughness $R_{a}$ was $0.04 \mu \mathrm{m}$, i.e. the particle was much smoother than the plate. We determined the contact radius $a$ for 100 particles by overlaying the profile of the particle in Fig. 15 on that of the plate in Fig. 13 at intervals of $2 \mu \mathrm{m}$. The cumulative distribution of the contact radius is shown in Fig. 16. The contact radius was distributed in a range of less than $3 \mu \mathrm{m}$, and the median radius, $a_{50}$, was $0.3 \mu \mathrm{m}$. From the median radius and the particle diameter, the term $D_{p 50} /\left(2 a_{50}\right)$ in Eq. (1) could be approximated as 100 . Therefore, the horizontal vibration force had a much greater effect on the removal efficiency than the vertical vibration force.

Lastly, we analyze the adhesive force using the moment balance model shown in Fig. 9. The horizontal $\left(F_{s x}\right)$ and vertical $\left(F_{s z}\right)$ components of the separation force and the gravitational force $\left(F_{g}\right)$ 
are given by

$$
\begin{aligned}
& F_{s x}=m_{p} \alpha_{x} \\
& F_{s z}=m_{p} \alpha_{z} \\
& F_{g}=m_{p} g
\end{aligned}
$$

where $m_{p}$ is the mass of the particle $\left(=\pi \rho_{p} D_{p}^{3} / 6\right)$ and $g$ is the gravitational acceleration $\left(=9.8 \mathrm{~m} / \mathrm{s}^{2}\right)$. The adhesive force $\left(F_{a}\right)$ is obtained by substituting Eqs. (5)-(7) into Eq. (1), i.e.

$$
F_{a}=\frac{m_{p}}{2}\left[\left(\sqrt{\left(\frac{D_{p}}{2 a}\right)^{2}-1}\right) \alpha_{x}+\alpha_{z}-\left.g\right|_{]}\right.
$$

For a typical value of the vertical acceleration, $\alpha_{z}=77 \mathrm{~m} / \mathrm{s}^{2}$, the median value of the horizontal vibration acceleration $\alpha_{x}$ is $27 \mathrm{~m} / \mathrm{s}^{2}$ (see Fig. 11). Substituting these values, the particle properties $\left(m_{p}\right.$ $=5.7 \times 10^{-10} \mathrm{~kg}, D_{p}=57 \mu \mathrm{m}$ ), and $D_{p} /(2 a)=100$ into Eq. (8), we obtain $F_{a}=7.9 \times 10^{-7} \mathrm{~N}$. On the other hand, the gravitational force $F_{g}$ is $5.6 \times 10^{-9} \mathrm{~N}$. Therefore, the adhesive force is much larger than the gravitational force. Furthermore, we analyze the adhesive force using Eq. (3). Substituting $F_{a}=7.9 \times 10^{-}$ ${ }^{7} \mathrm{~N}, D_{p}=57 \mu \mathrm{m}$, and Hamaker constant $A$, the range from $6 \times 10^{-20}$ to $15 \times 10^{-20} \mathrm{~J}$ for oxides (Masuda et al., 2006) into Eq. (3), we obtain the range of separation gap $z_{0}$, i.e. from 0.6 to $0.9 \mathrm{~nm}$. If there are many contact points between the actual surfaces, the range of the separation gap will be larger. Taking into account the surface roughness, we think that the analyzed result is reasonable.

\section{Conclusion}

The detachment of micrometer-sized spherical particles from an obliquely oscillating plate was analyzed through microscopic observation. The particles rolled on the surface before detachment. The analysis of the trajectories and velocities of the particles and plate shows that after the particle rolled on the plate, the particle could detach within one oscillation cycle because the rolling significantly reduced the adhesive force between the particle and plate. Furthermore, an analysis using a moment balance model that considers the contact radius between the particles and plate shows that the 
horizontal vibration acceleration had a much greater effect on the rolling than the vertical vibration acceleration. Consequently, the removal efficiency, which is defined by the number ratio of detached particles to total particles, significantly increased with the horizontal vibration acceleration.

\section{Nomenclature}

A Hamaker constant

$A_{x}$ horizontal vibration amplitude

$A_{z} \quad$ vertical vibration amplitude

a contact radius between particle and plate

$a_{50}$ median contact radius between particle and plate

$D_{p} \quad$ diameter of particle

$D_{p 50}$ mass median diameter of particle

$F \quad$ distribution function

$F_{a}$ adhesive force between particle and plate

$F_{g}$ gravitational force

$F_{s x}$ horizontal vibration force

$F_{\text {sz }} \quad$ vertical vibration force

g gravitational acceleration $\left(\mathrm{m} / \mathrm{s}^{2}\right)$

$h$ height

$L \quad$ length

$m_{p} \quad$ mass of a particle

$N_{0} \quad$ initial number of adhering particles

$N_{\mathrm{r}} \quad$ number of residual particles

$R_{a} \quad$ average roughness 
$t$ time

$v_{z} \quad$ vertical velocity

$d_{x}$ horizontal displacement

$d_{z} \quad$ vertical displacement

$Z_{0}$ gap distance

$\alpha_{x}$ horizontal vibration acceleration

$\alpha_{z} \quad$ vertical vibration acceleration

$\eta \quad$ particle removal efficiency

$\rho_{p} \quad$ particle density

$\left(\mathrm{kg} / \mathrm{m}^{3}\right)$

$\varphi \quad$ oscillation phase angle

(rad)

\section{Acknowledgments}

This work was supported by JSPS KAKENHI Grant number 25-1710. The authors acknowledge the financial support. In addition, the authors are thankful to Tosoh Corporation and Two Nine Japan Company Limited for providing the particles and the surface treatment of the metal plate, respectively.

\section{References}

Chung, Y.C., Liao, H.H., Hsiau, S.S., 2013. Convection behavior of non-spherical particles in a vibrating bed: discrete element modeling and experimental validation. Powder Technol. 237, 53-66. Gallas, J.A.C., Herrman, H.J., Sokolowski, S., 1992. Two-dimensional powder transport on a vibrating belt. J. Phys. II 2, 1389-1400.

Hubbard, J.A., Brockmann, J.E., Rivera, D., Moore, D.G., 2012. Experimental study of impulse resuspesion with laser Doppler vibrometry. Aerosol Sci. Technol. 46, 1303-1312.

Ishii, K., Suzuki, M., Segawa, T., Kihara, Y., Yasuda, M., Matsusaka, S., 2011. A vibrating tube method 
for evaluating flowability of a small amount of sample particles. Adv. Powder Technol. 22, 522-525.

Jiang, Y., Matsusaka, S., Masuda, H., Yokoyama, T., 2006. Evaluation of flowability of composite particles and powder mixtures by a vibrating capillary method, J. Chem. Eng. Jpn. 39, 14-21.

Jiang, Y., Matsusaka, S., Masuda, H., Qian, Y., 2008. Characterizing the effect of substrate surface roughness on particle-wall interaction with the airflow method. Powder Technol. 186, 199-205.

Jiang, Y., Matsusaka, S., Masuda, H., Qian, Y., 2009. Development of measurement system for powder flowability based on vibrating capillary method. Powder Technol. 188, 242-247.

Kobayakawa, M., Yasuda, M., Matsusaka, S., 2014a. Microscopic analysis of saltation of particles on an obliquely oscillating plate. Adv. Powder Technol. 25, 1845-1853.

Kobayakawa, M., Fujimoto, A., Sakata, M., Yasuda, M., Matsusaka, S., 2014b. Numerical and theoretical study of particle saltation on an obliquely oscillating plate. Adv. Powder Technol. 25, 1854-1859.

Kousaka, Y., Okuyama, K., Endo, Y., 1980. Re-entrainment of small aggregate particles from a plane surface by air stream. J. Chem. Eng. Jpn. 13, 143-147.

Liao, C.C., Hsiau, S.S., Tsai, T.H., Tai, C.H., 2010. Segregation to mixing in wet granular matter under vibration, Chem. Eng. Sci. 65, 1109-1116.

Limtrakul, S., Rotjanavijit, W., Vatanatham, T., 2007, Lagrangian modeling and simulation of effect of vibration on cohesive particle movement in a fluidized bed. Chem. Eng. Sci. 62, 232-245.

Liu, Y. H., Hirama, D., Matsusaka, S., 2012. Particle removal process druring application of impinging dry ice jet. Powder Technol. 217, 607-613.

Liu, Y. H., Maruyama, H., Matsusaka, S., 2011. Effect of particle impact on surface cleaning using dry ice jet. Aerosol Sci. Technol. 45, 1519-1527.

Maniero, R., Climent, E., Bacchin, P., 2012. Adhesion and detachment fluxes of micro-particles from a permeable wall under turbulent flow conditions. Chem. Eng. Sci. 71, 409-421. 
Masuda, H., Gotoh, K., Higashitani, K., Matsusaka, S., Adhesive force of a single particle, in: Masuda, H., Higashitani, K., Yoshida, H. (Eds.), Powder Technology Handbook, 3rd ed., CRC Press, Boca Raton, 2006, 157-170

Matsusaka, S., Aoyagi, T., Masuda, H., 1991. Unsteady particle-reentrainment model based on the internal adhesive strength distribution of a fine powder layer. Kagaku Kougaku Ronbunshu 17, 11942000.

Matsusaka. S., Kobayakawa, M., Mizutani, M., Imran, M., Yasuda, M., 2013. Bubbling behavior of a fluidized bed of fine particles caused by vibration-induced air inflow, Sci. Rep. 3, 1190.

Matsusaka, S., Koumura, M., Masuda, H., 1997. Analysis of adhesive force between particle and wall based on particle reentrainment by airflow and centrifugal separation. Kagaku Kougaku Ronbunshu 23, 561-568.

Matsusaka, S., Masuda, H., 1996. Particle reentrainment from a fine powder layer in a turbulent air inflow. Aerosol Sci. Technol. 24, 69-84.

Matsusaka, S., Urakawa, M., Masuda, H., 1995. Micro-feeding of fine powders using a capillary tube with ultrasonic vibration. Adv. Powder Technol. 6, 283-293.

Matsusaka, S., Yamamoto, K., Masuda, H., 1996. Micro-feeding of a fine powder using a vibrating capillary tube. Adv. Powder Technol. 7, 141-151.

Mullins, M.E., Michaels, L.P., Menon, V., Locke, B., Ranade, M.B., 1992. Effect of geometry on particle adhesion. Aerosol Sci. Technol. 17, 105-118.

Pak, H.K., Behringer, P.R., 1994. Bubbling in vertically vibrated granular materials. Nature 371, 231233.

Quintanilla, M.A.S., Valverde, J.M., Castellanos, A., Lepek, D., Pferffer, R., Dave, R.N., 2008. Nanofluidization as affected by vibration and electrostatic fileds. Chem. Eng. Sci. 63, 5559-5569.

Rademacher, F.J.C., ter Borg, L., 1994. On the theoretical and experimental conveying speed of 
granular bulk solids on vibratory conveyors. Forsch Ing. 60, 261-283.

Rosato, A.D., Blackmore, D.L., Zhang, N., Lan, Y., 2002. A perspective on vibration-induced size segregation of granular materials. Chem. Eng. Sci. 57, 265-275.

Salazar-Banda, G.R., Felicetti, M.A., Goncalves, J.A.S., Coury, J.R., Aguiar, M.L., 2007. Determination of the adhesion force between particles and a flat surface, using the centrifuge technique. Powder Technol. 173, 107-117.

Simsek, E., Wirtz, S., Scherer, V., Kruggel Emden, H., Grochowski, R., Walzel, P., 2008. An experimental and numerical study of transversal dispersion of granular material on a vibrating conveyor. Part. Sci. Technol. 26, 177-196.

Sloot, E.M., Kruyt, N.P., 1996. Theoretical and experimental study of the transport of granular materials by inclined vibratory conveyors. Powder Technol. 87, 203-210.

Soltani, M., Ahmadi, G., 1994. Particle removal mechanisms under substrate acceleration. J. Adhes. 44, 161-175.

Soltani, M., Ahmadi, G., Bayer, R.G., Gaynes, M.A., 1995. Particle detachment mechanisms from rough surfaces under substrate acceleration. J. Adhes. Sci. Technol. 9, 453-473.

Tatemoto, Y., Mawatari, Y., Yasukawa, T., Noda, K., 2004. Numerical simulation of particle motion in vibrated fluidized bed, Chem. Eng. Sci. 59, 437-447.

Tatemoto, Y., Mawatari, Y., Noda, K., 2005. Numerical simulation of cohesive particle motion in vibrated fluidized bed, Chem. Eng. Sci. 60, 5010-5021.

Theerachaisupakij, W., Matsusaka, S., Akashi, H., Masuda, H., 2003. Reentrainment of deposited particles by drag and aerosol collision. J. Aerosol Sci. 34, 261-274.

Theerachaisupakij, W., Matsusaka, S., Kataoka, M., Masuda, H., 2002. Effects of wall vibration on particle deposition and reentrainment in aerosol flow. Adv. Powder Technol. 13, 287-300.

Tsai, C.J., Pui, D.Y.H., Liu, B.Y.H., 1991. Particle detachment from disk surfaces of computer disk 
drives. J. Aerosol Sci. 22, 737-746.

Wang, H.-C., 1990. Effects of inceptive motion on particle detachment from surfaces, Aerosol Sci. Technol. 13, 386-393.

Yang, S.C., 2006. Segregation of cohesive powders in a vibrated granular bed. Chem. Eng. Sci. 61, 6180-6188.

Yang, S.C., Hsiau, S.S., 2000. Simulation study of the convection cells in a vibrated granular bed.

Chem. Eng. Sci. 55, 3627-3637.

Yang, S.C., Hsiau, S.S., 2001. The simulation of powders with liquid bridges in a 2D vibrated bed. Chem. Eng. Sci. 56, 6837-6849.

Zainuddin, I.M., Yasuda, M., Horio, T., Matsusaka, S., 2012. Exeperimental study on powder flowability using vibration shear tube method. Part. Part. Syst. Charact. 29, 8-15.

Zamankhan, P., 2011a. Bubbles and solid structures in a vibrated bed of granular materials. Physica A 390, 1402-1416.

Zamankhan, P., 2011b. Bubbling in vibrated granular films. Phys. Rev. E 83, 021306. 


\section{Figure contents}

Fig. 1. Schematic diagram of the experimental setup.

Fig. 2. SEM image of zirconia particles.

Fig. 3. Cumulative size distribution of zirconia particles.

Fig. 4. Horizontal displacement of the oscillating plate as a function of time.

Fig. 5. Lissajous figures of the obliquely oscillating plate.

Fig. 6. Snapshots of the process of particle detachment from the oscillating plate during one oscillation cycle.

Fig. 7. Trajectories of the oscillating plate and the particle as a function of the phase angle of the oscillation: (a) horizontal displacement and (b) vertical displacement.

Fig. 8. (a) Vertical velocities of the oscillating plate and the particle as a function of time; (b) magnified figure of Fig. 7(b).

Fig. 9. Forces acting on a particle adhering to the obliquely oscillating surface.

Fig. 10. Relationship between particle removal efficiency and vertical amplitude as a parameter of horizontal amplitude.

Fig. 11. Relationship between particle removal efficiency and horizontal amplitude as a parameter of vertical amplitude.

Fig. 12. Three dimensional image of surface roughness of the plate.

Fig. 13. Profiles of surface roughness of the plate.

Fig. 14. Three dimensional image of surface roughness of the test particle.

Fig. 15. Profiles of surface roughness of the test particle.

Fig. 16. Cumulative distribution of contact radius between the particles and plate. 
Fig. 1.

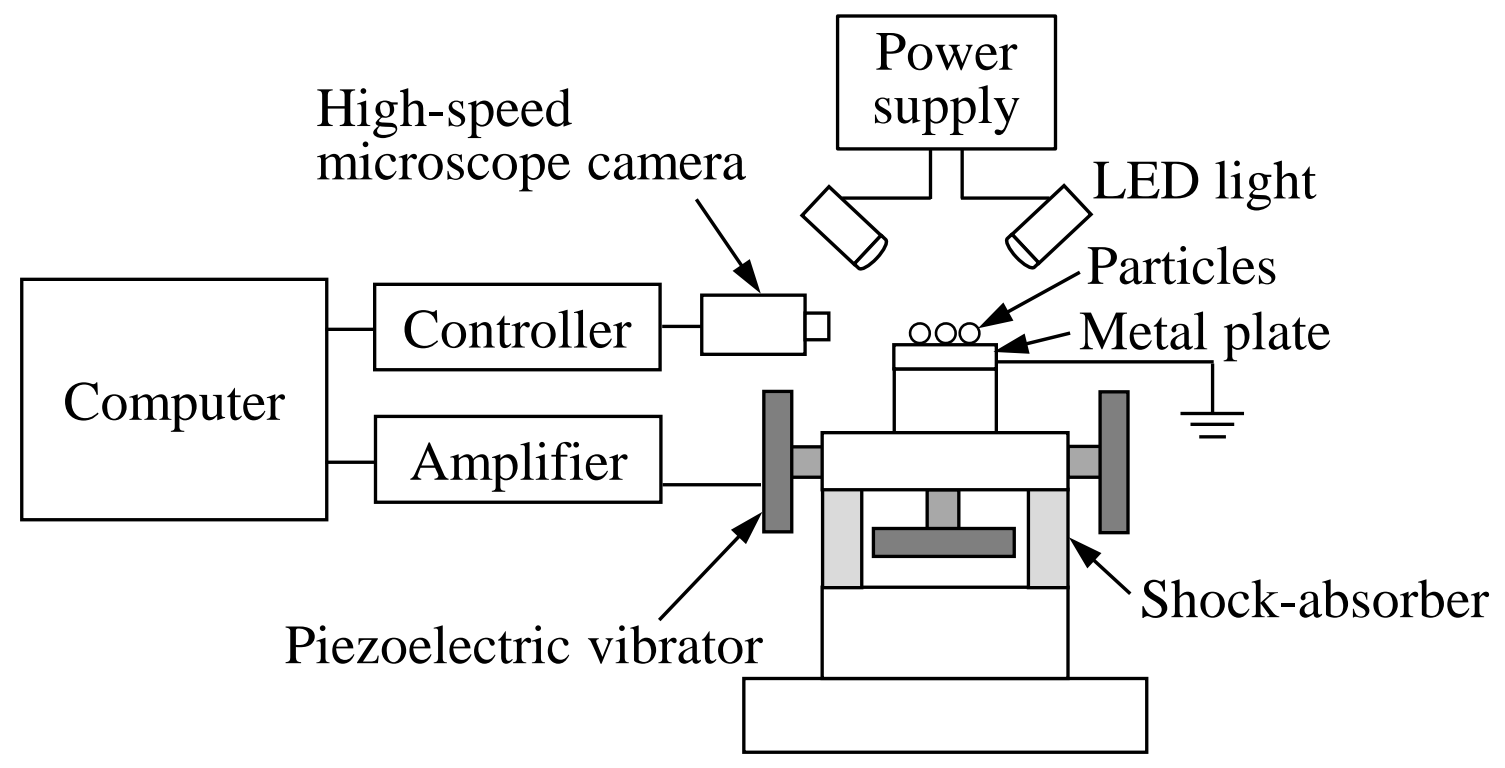


Fig. 2.

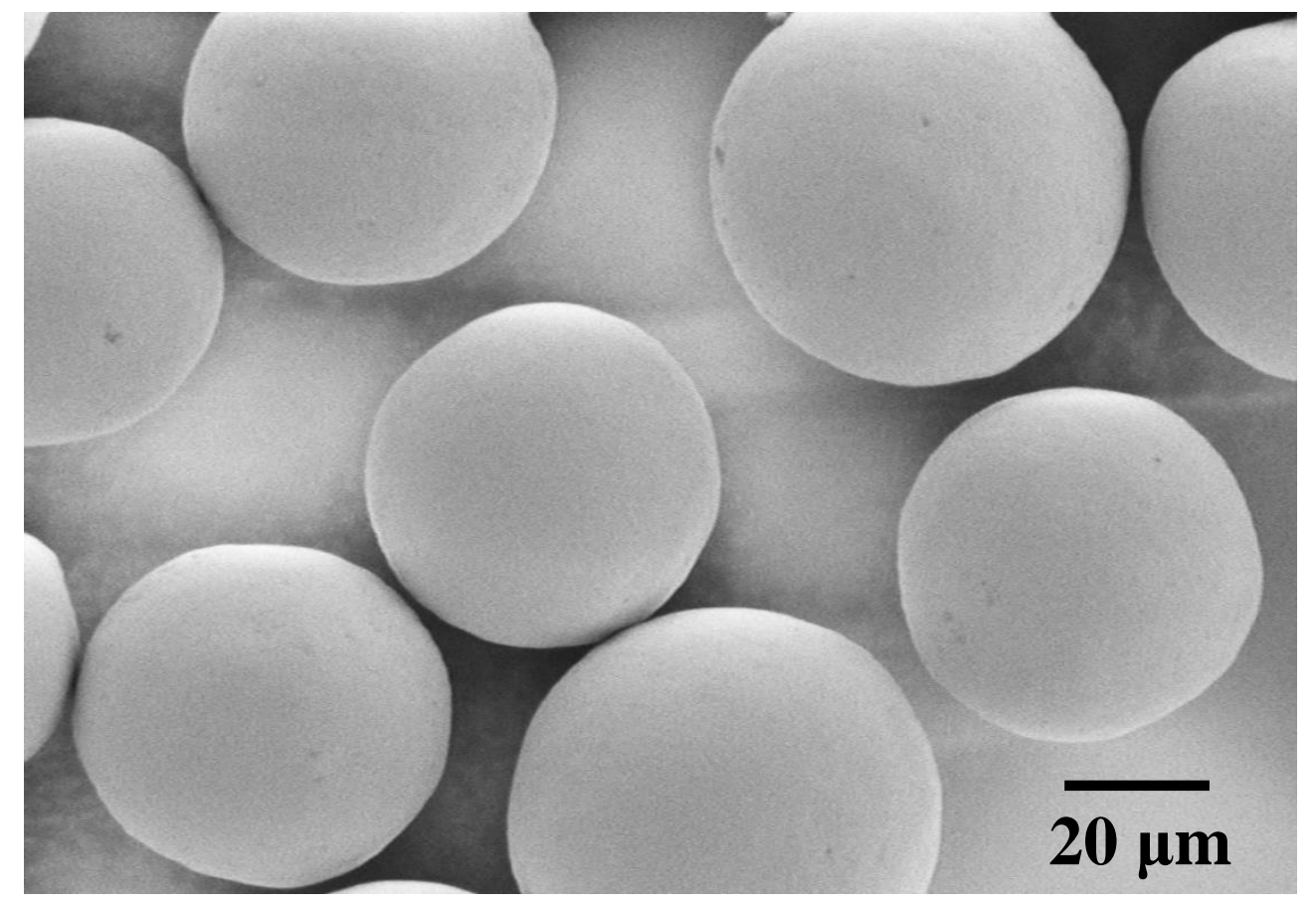


Fig. 3.

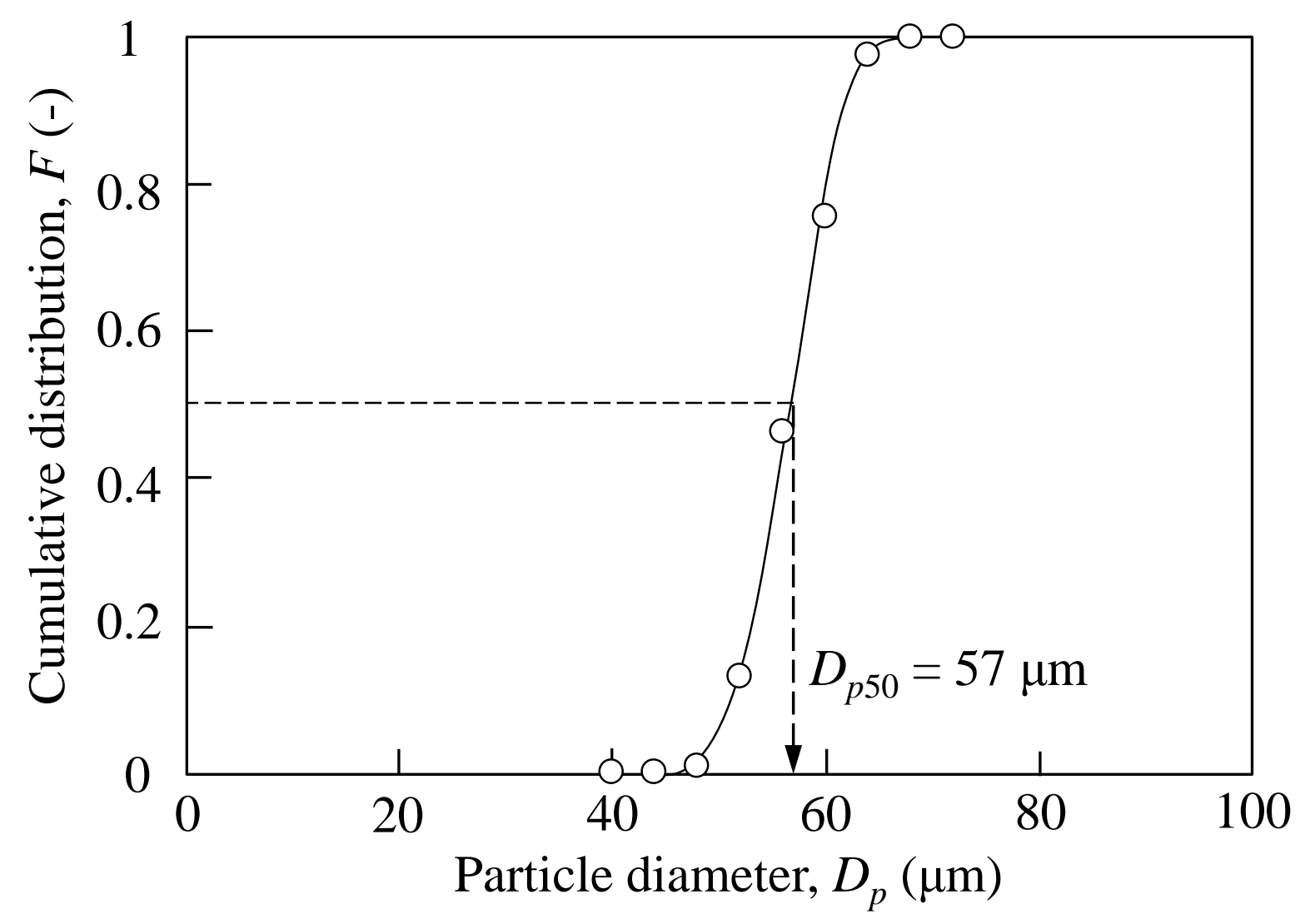


京都大学
KYoTO UNIVERSIYY

Fig. 4.

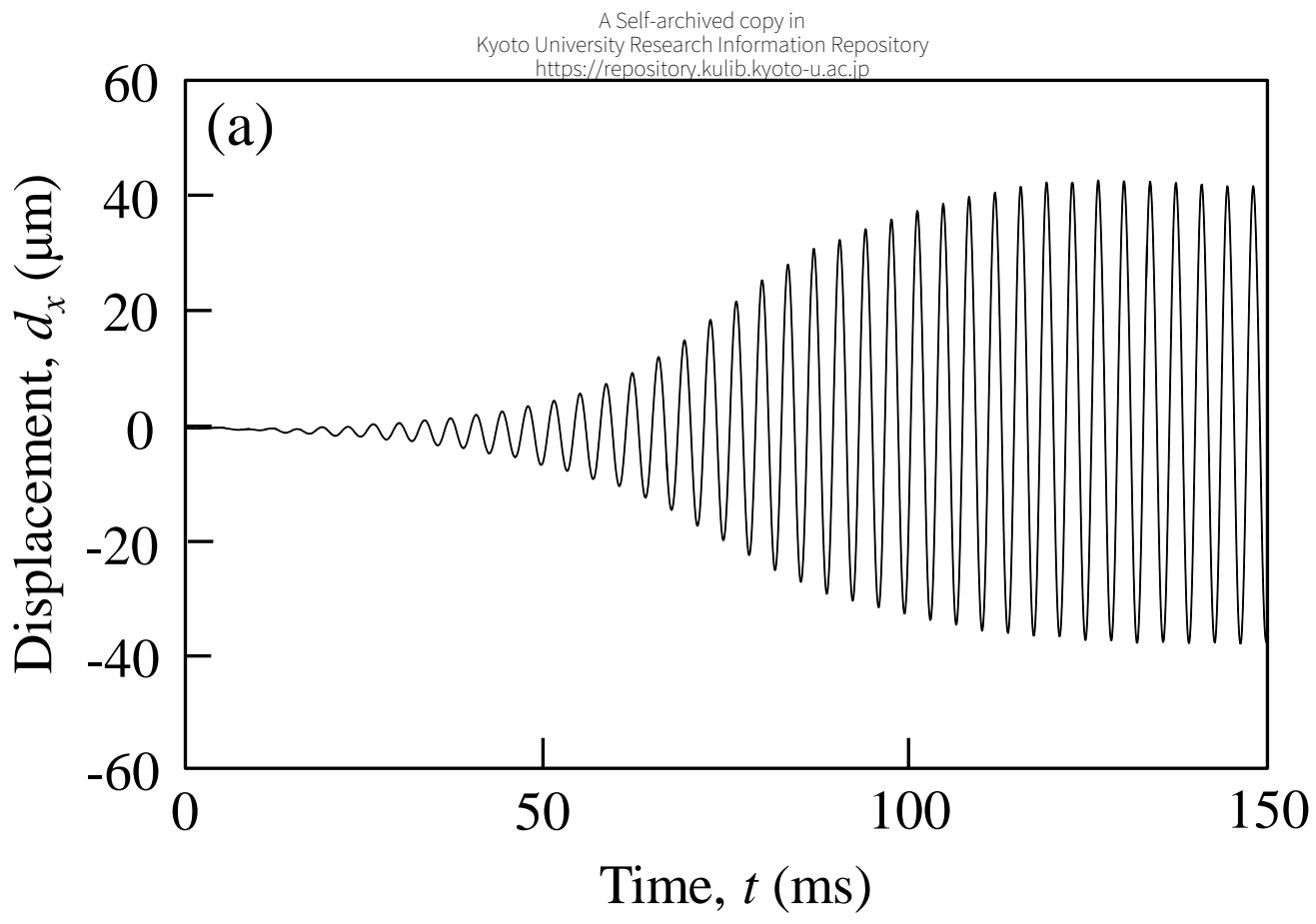

KURENAI 红

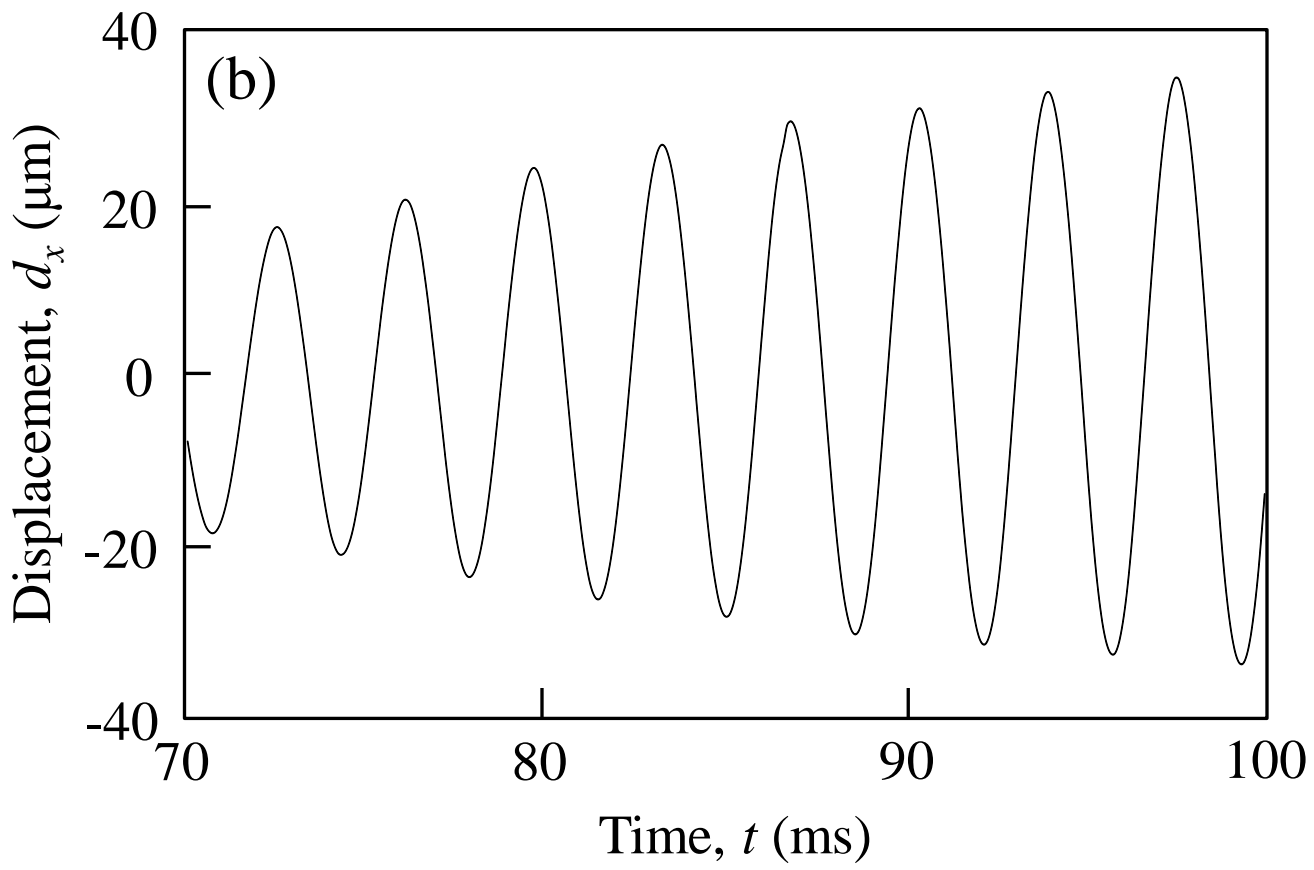


Fig. 5.

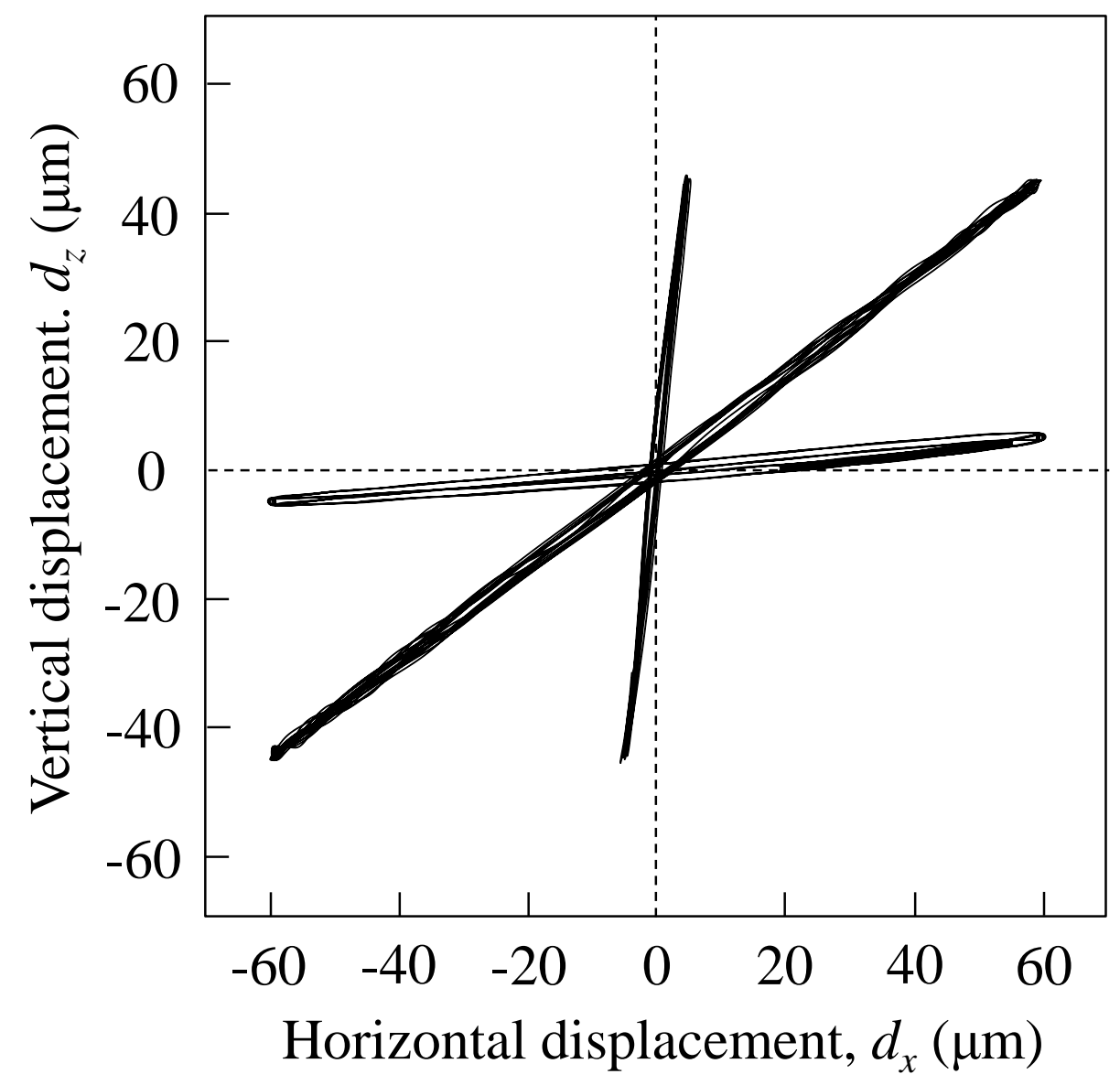


Fig. 6.

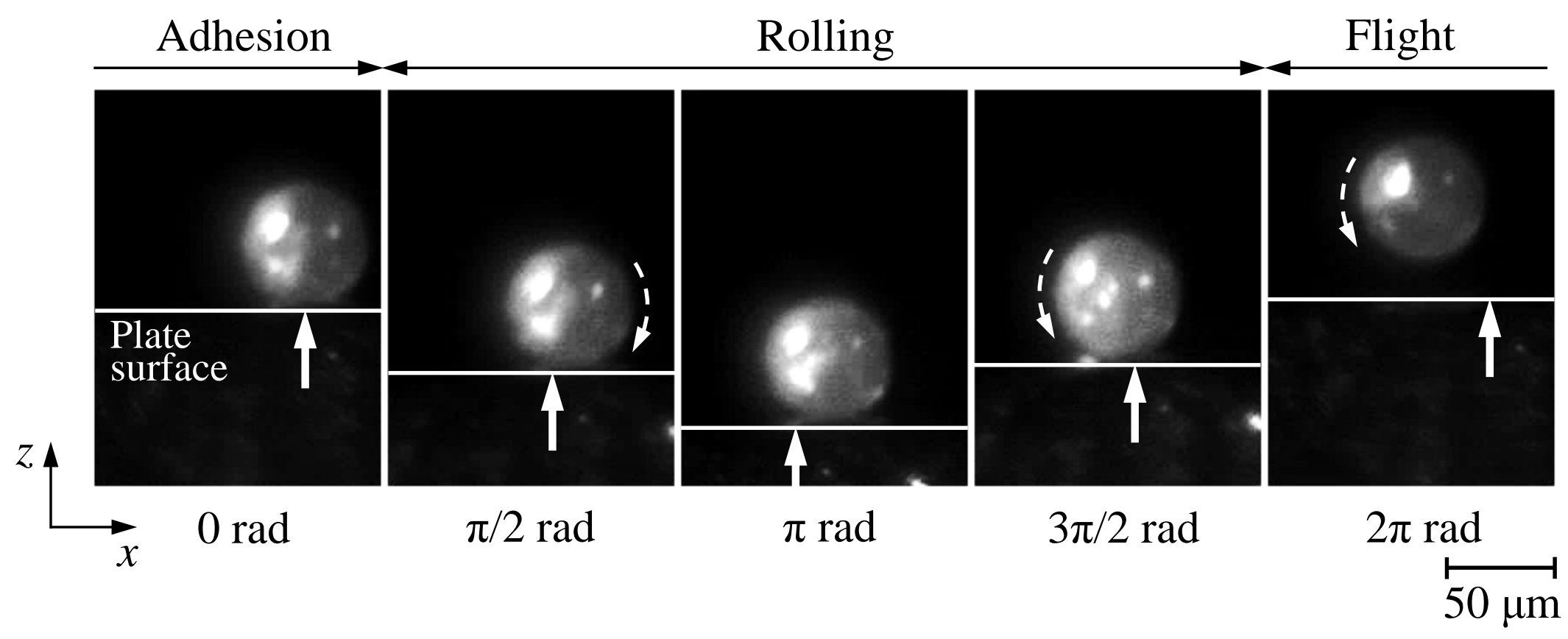


Fig. 7.
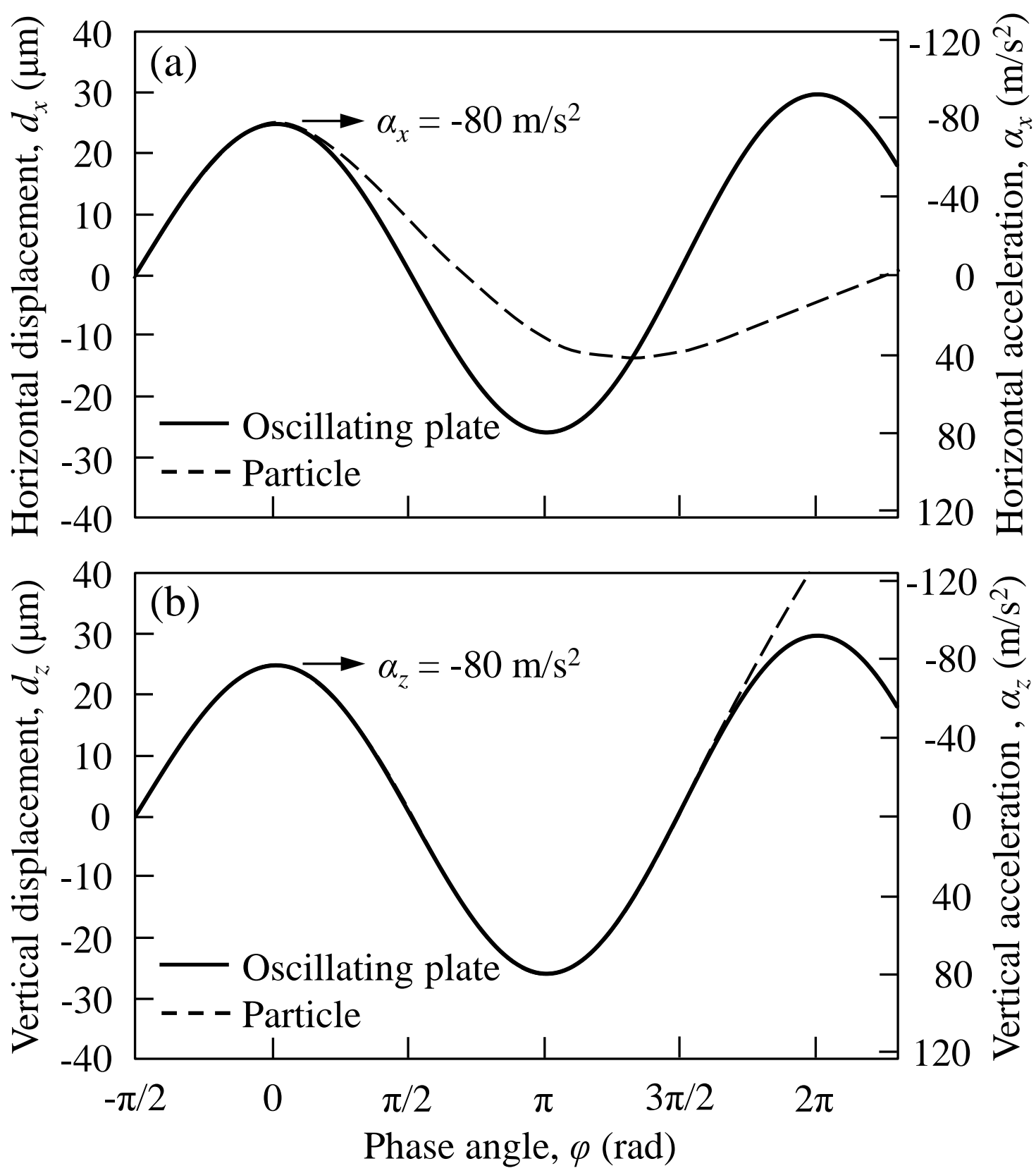
Fig. 8.
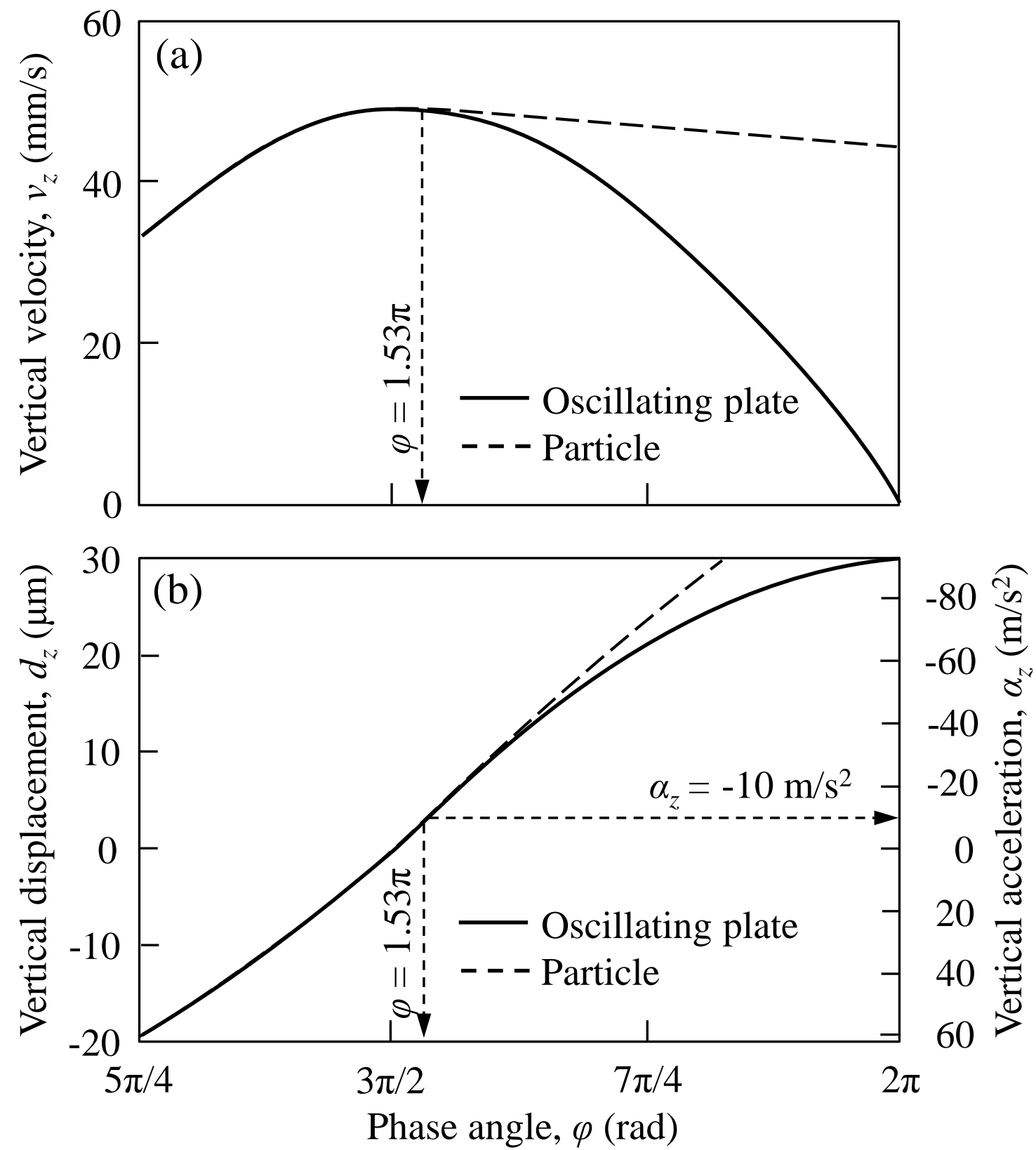
Fig. 9.

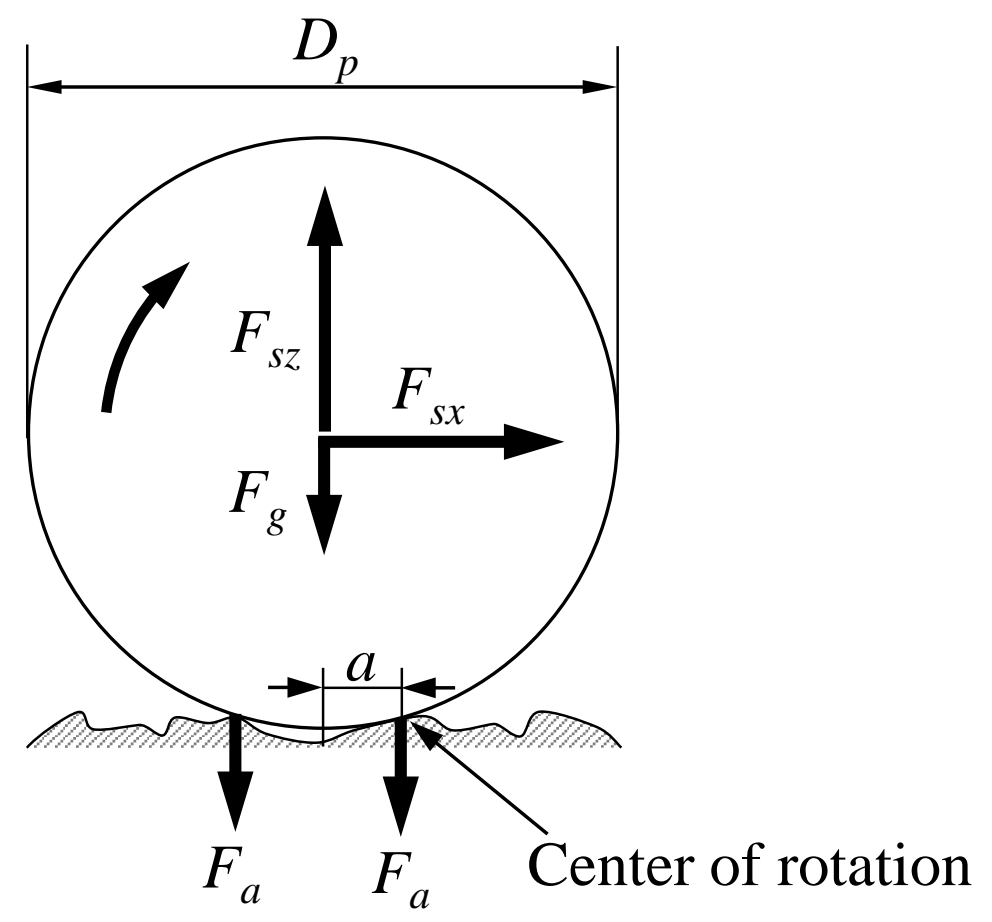


Fig. 10.

Vertical acceleration, $\alpha_{z}\left(\mathrm{~m} / \mathrm{s}^{2}\right)$

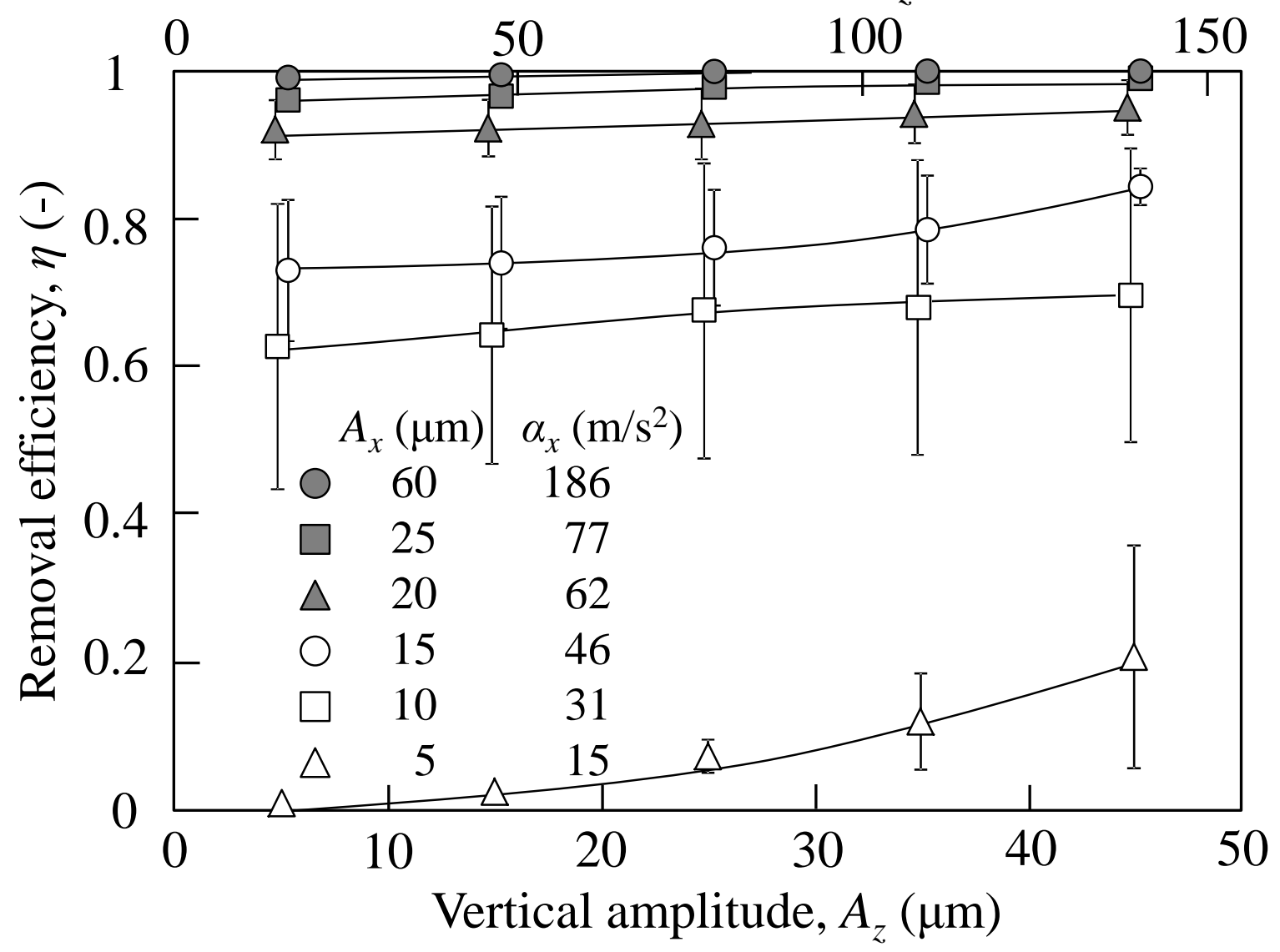


Fig. 11.

Horizontal acceleration, $\alpha_{x}\left(\mathrm{~m} / \mathrm{s}^{2}\right)$

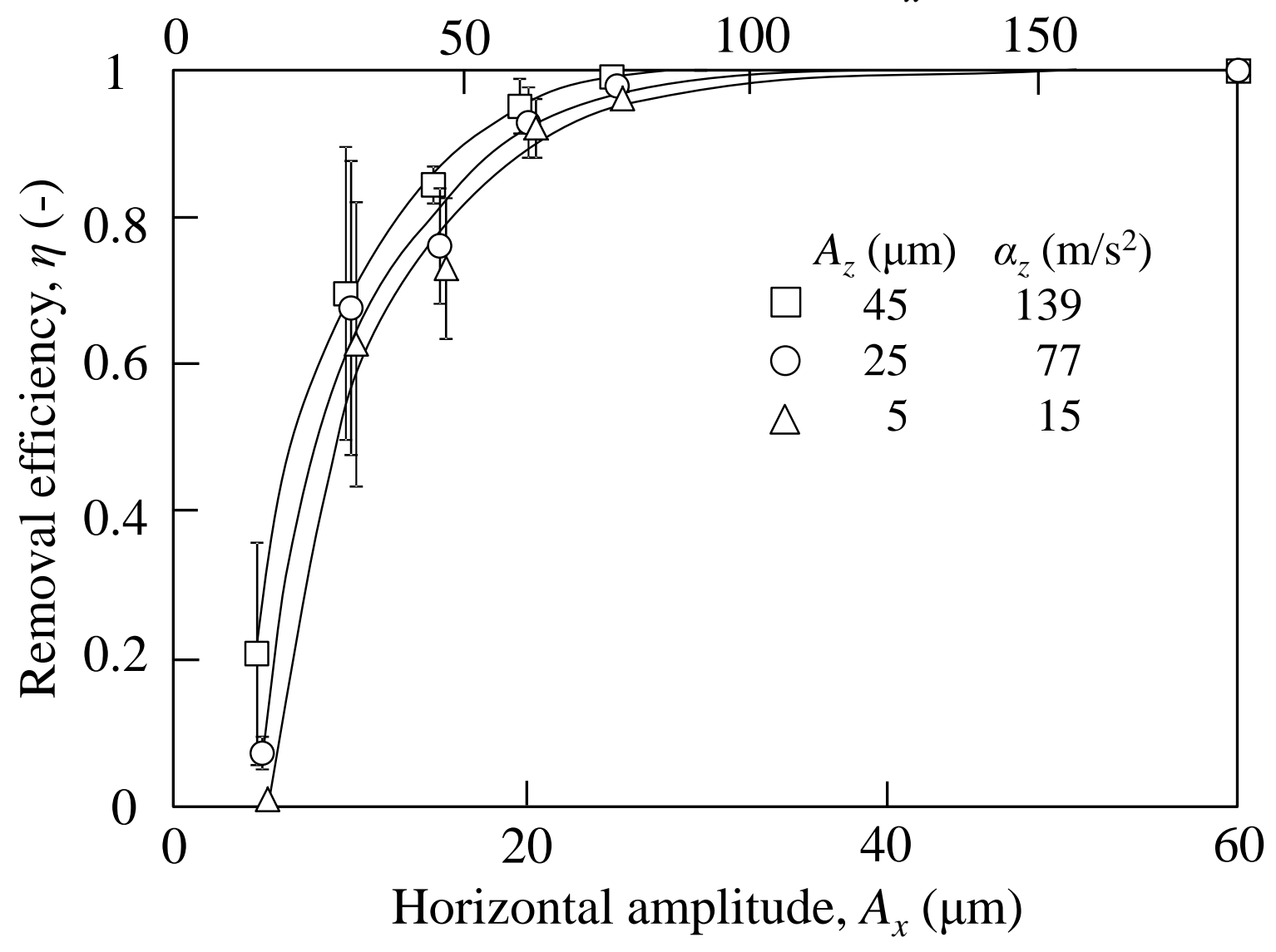




\section{Fig. 12.}

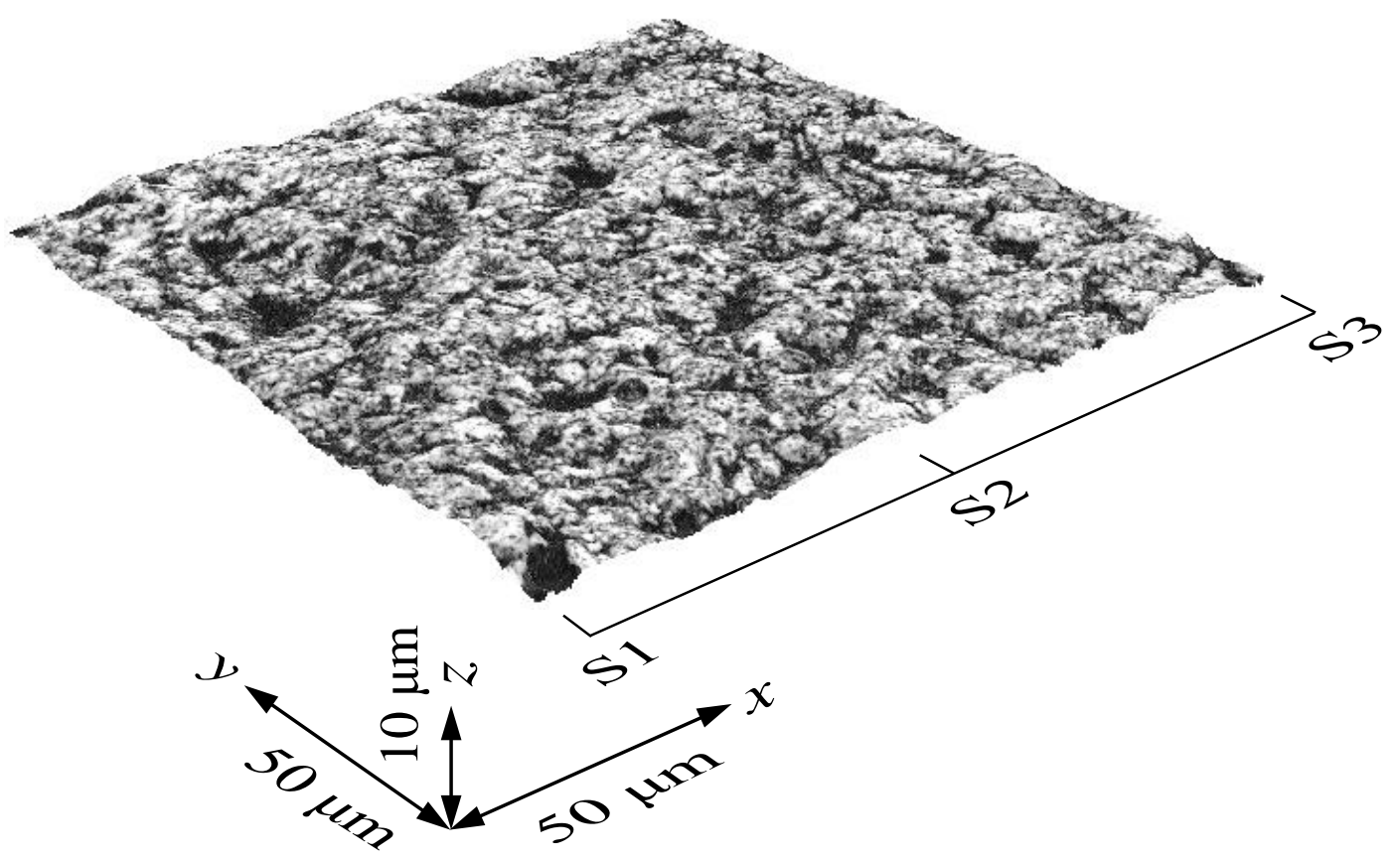


Fig. 13.

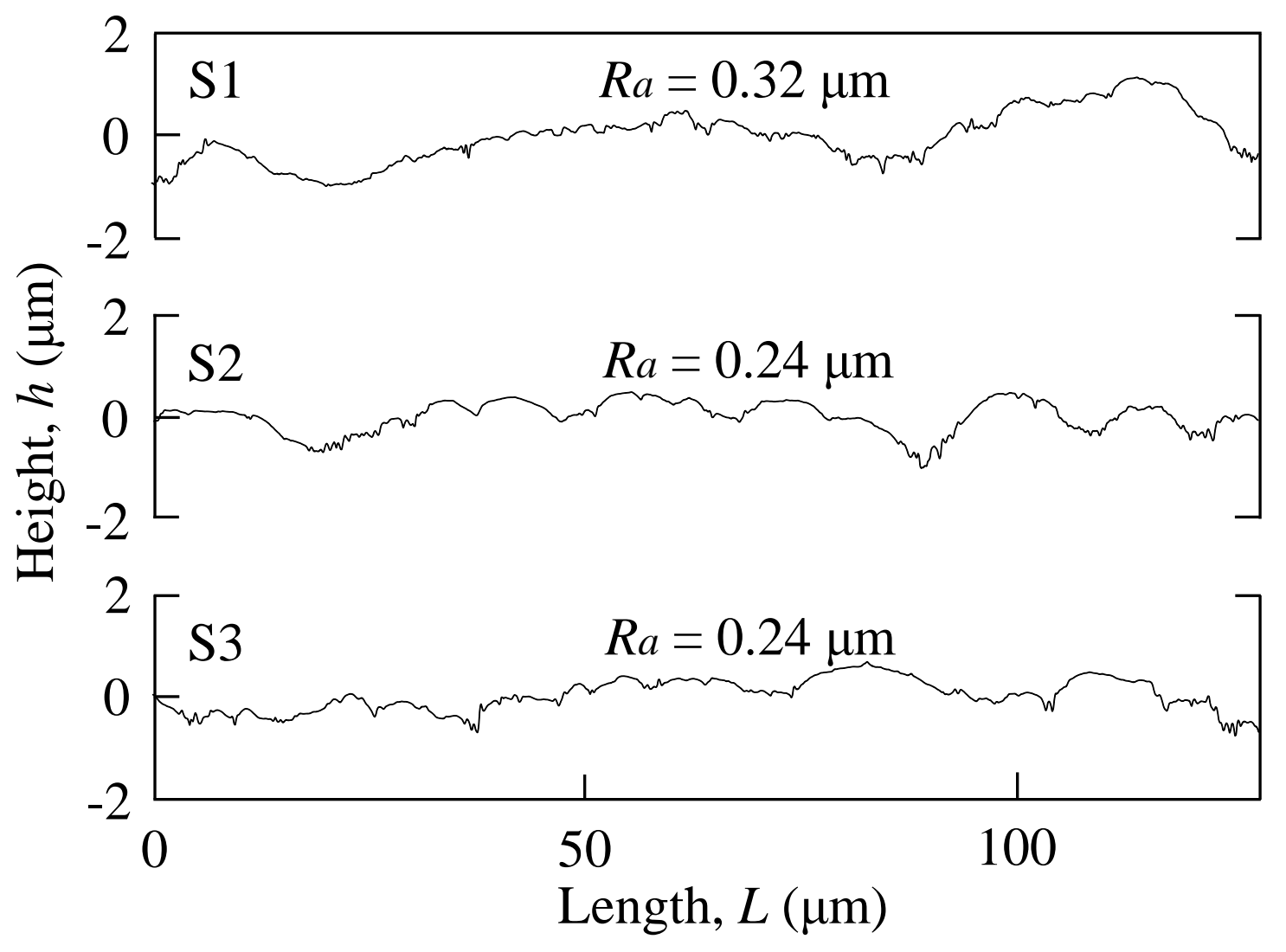


Fig. 14.

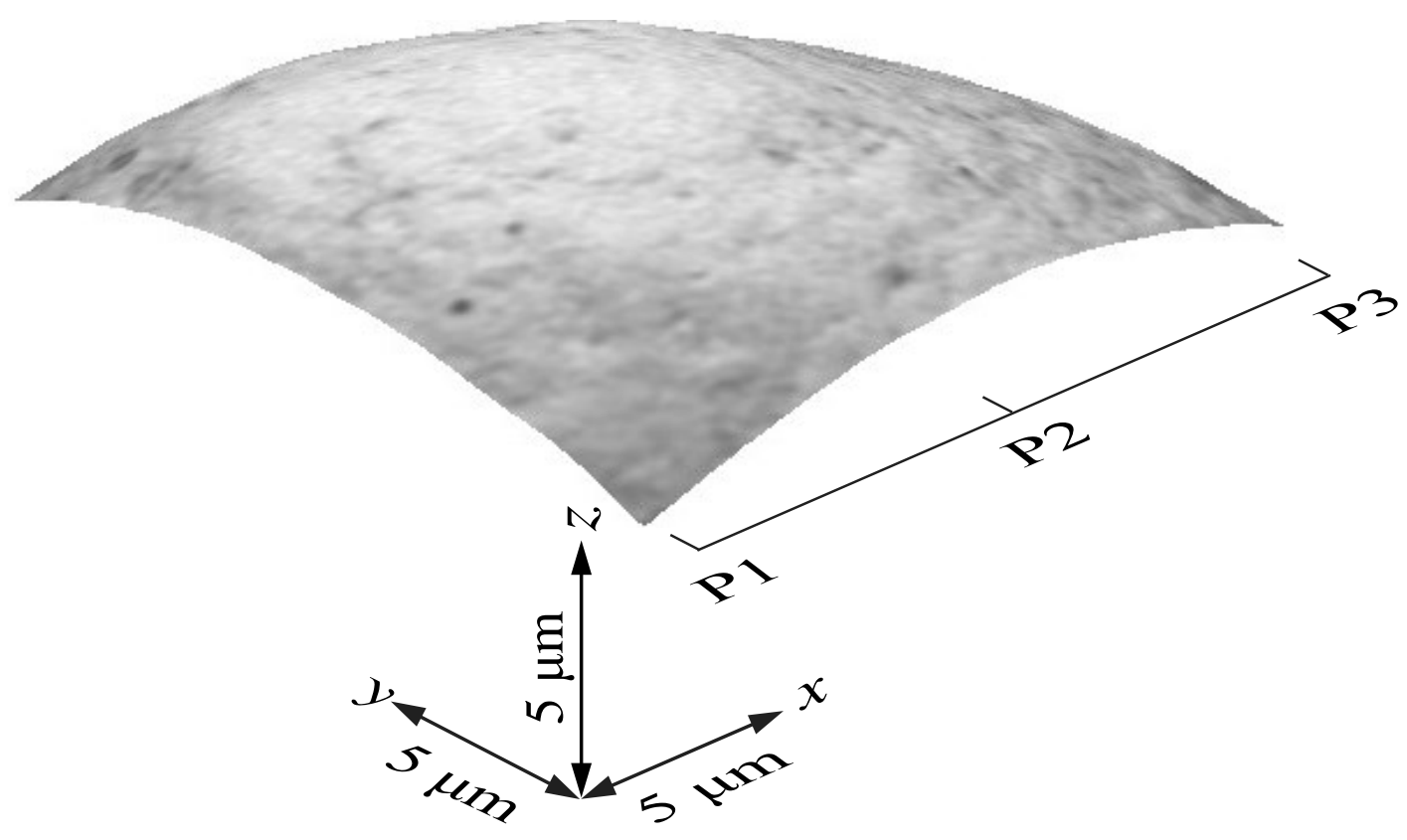


Fig. 15.

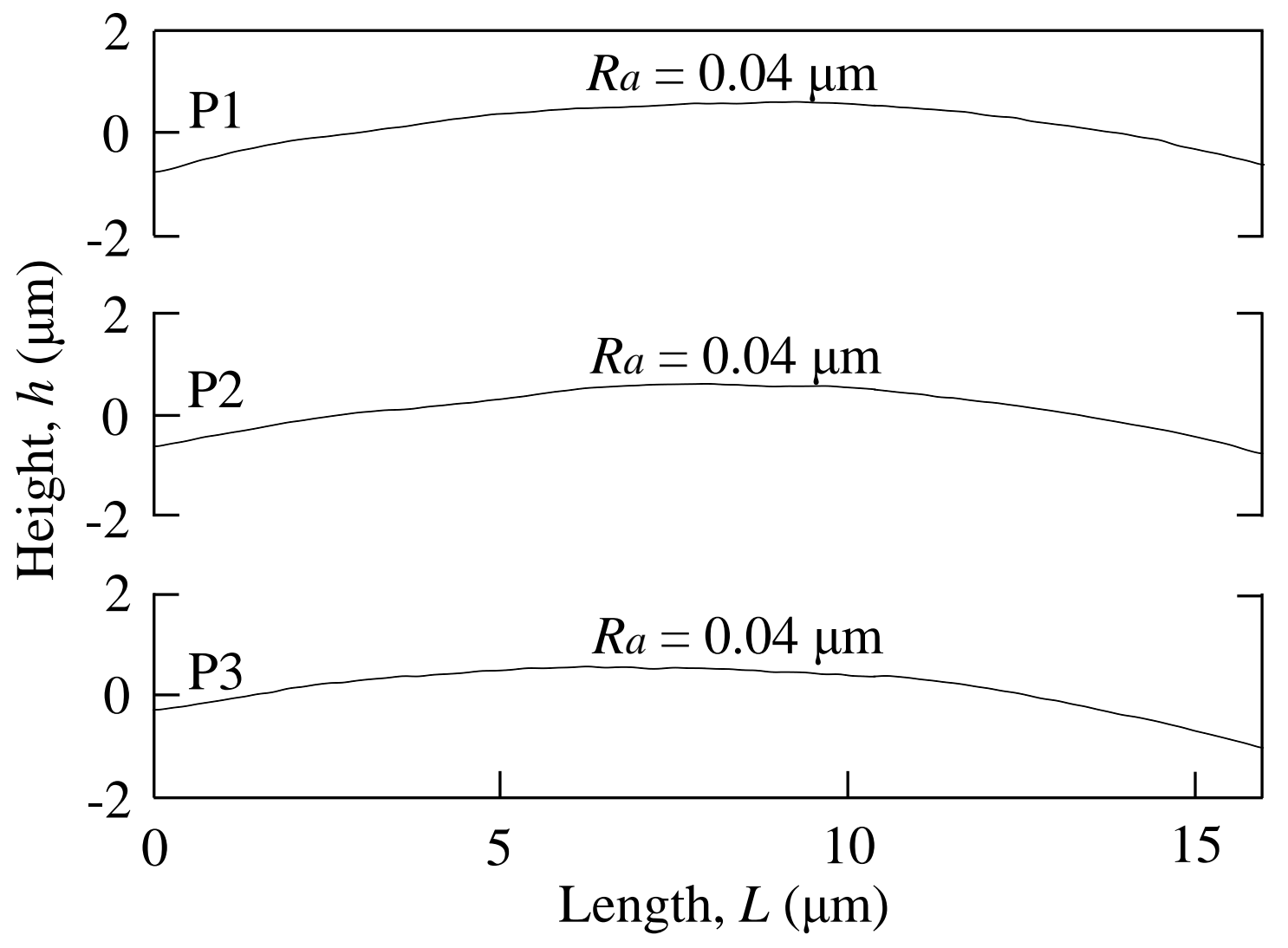


Fig. 16.

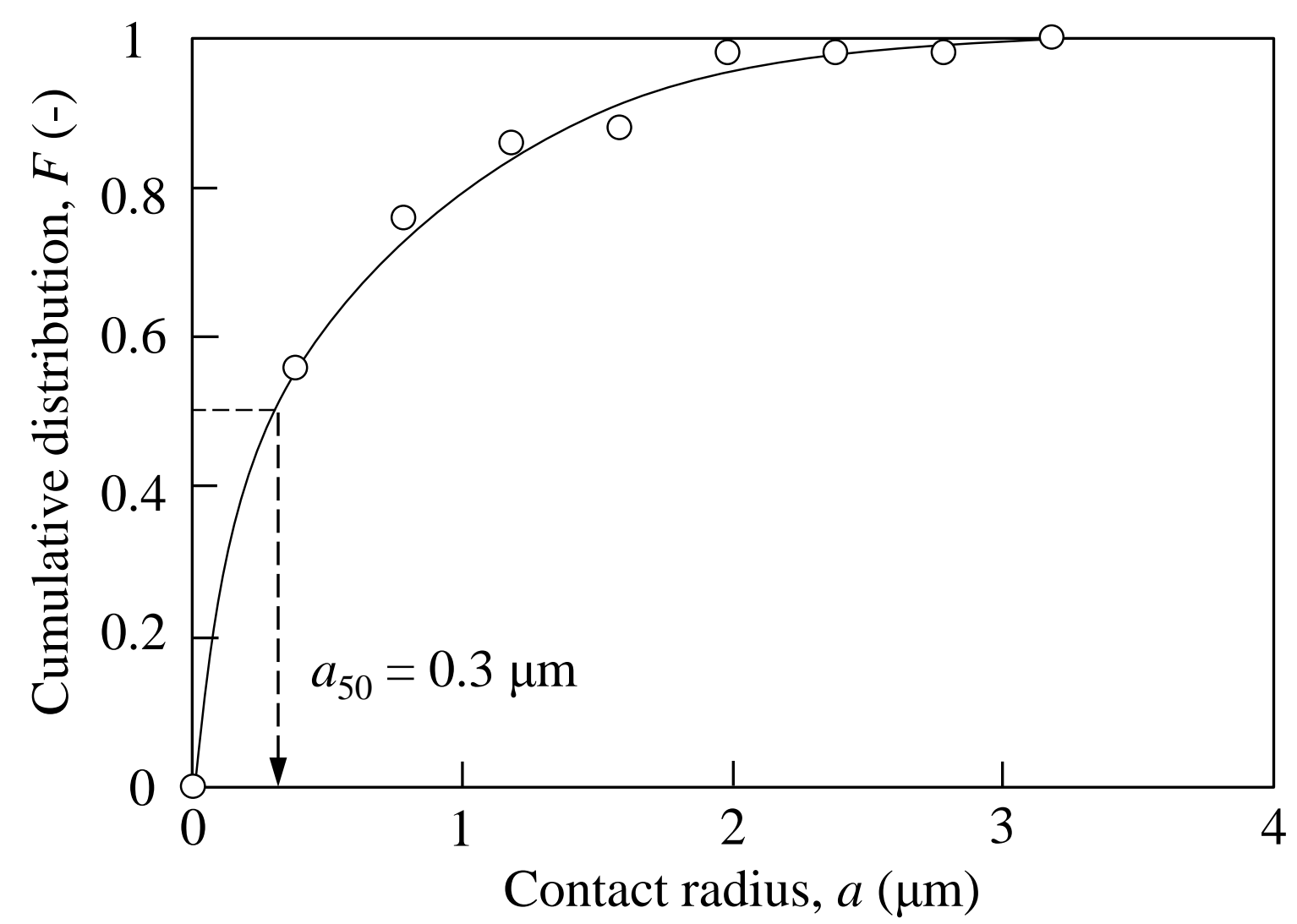

